\title{
Fallout: the new cost of brood parasitism
}

\author{
Marcel Honza ${ }^{1}$, Miroslav Capek $^{1}$, Vaclav Jelinek ${ }^{1}$, and Michal Sulc ${ }^{1}$ \\ ${ }^{1}$ Institute of Vertebrate Biology CAS
}

May 5, 2020

\begin{abstract}
Animals rely on an array of environmental triggers or cues to make their behavioural and life-history decisions. In the case of brood parasites, it is adaptive to use a suitable host to guarantee maximum fitness. Despite the fact that the Eurasian reed warbler (Acrocephalus scirpaceus) is the most frequent host of the common cuckoo (Cuculus canorus), we video recorded that cuckoo young often fall out of the nests of this host before fledging time and drown. To establish whether these events are influenced by the size of the nest, we replaced original Eurasian reed warbler nests for much bigger great reed warbler (Acrocephalus arundinaceus) nests and transferred cuckoo chicks into them. Subsequently, we video-recorded the fate of these cuckoo chicks. In these bigger nests, we recorded a significantly lower falling-out rate (4 of 29) compared with those remained in the real reed warbler nests (12 of 32). This result suggests that host nest size plays an important role in the suitability of reed warbler host species and that Eurasian reed warbler nests have a high mortality risk to the relatively big cuckoo chicks. Moreover, we found that cuckoo chicks that fell out of the nests were significantly less fed by foster parents during the three hours before falling-out event than chicks that stayed in the nests. This suggests that also insufficient parental care in terms of lower feeding intensity may facilitate falling-out of cuckoo chicks, probably because hungry chicks are more restless in host nests. The relatively high falling-out rate represents a substantial and underestimated cost of brood parasites. Moreover, without video surveillance it can be incorrectly confused with predation. Therefore, we strongly recommend using video-recording for estimating predation costs in birds.
\end{abstract}

Key words: Acrocephalus scirpaceus, Cuculus canorus, brood parasitism, chick survival, nest, coevolution

${ }^{1}$ Institute of Vertebrate Biology, Czech Academy of Sciences, Kvetna 8, 603 65, Brno, Czech Republic

\section{Correspondence: E-mail: honza@ivb.cz INTRODUCTION}

A major goal in studies of evolutionary ecology is to identify factors explaining variation in reproductive success, i.e. in the number of young produced (Santema \& Kempenaers 2018). Since the nest design has a crucial effect on the breeding success of birds (Hansell 2000), evolution selected for various nest designs to make them adaptive for their builders. Nests vary in their structure complexity, size, position and material they are made of. However, there are a small number of bird species (109; representing no more than $1 \%$ of the world's total bird species richness (Gill \& Donsker 2020) called obligate brood parasites (Mann 2017) that do not build their nests at all and instead lay their eggs in nests of other species - the hosts - and leave all parental care to foster parents.

Some brood parasites are generalists utilizing dozens of host species; however, only a few of these species can be considered as main hosts that are parasitized regularly (Jaramillo \& Burke 1999; Erritzøe et al. 2012). This is the case for the common cuckoo (Cuculus canorus), one of the most studied brood parasite species, breeding across the vast area from Western Europe to the Far East (Erritzøe et al. 2012). About 
280 bird species (at least 135 species in Europe alone) have been recorded to be parasitized by the common cuckoo, of which less than $10 \%$ are considered regular hosts (Erritzøe et al. 2012). These host species differ remarkably in their body mass (Snow and Perrins 1998b), timing of breeding (Snow \& Perrins 1998b) and their aggression towards intruders (e.g. Capek et al. 2010; Požgayová et al. 2009; Gloag et al. 2013) which affects the strategies required for brood parasites to breed successfully.

Researchers studying host suitability for brood parasites have focused mainly on host quality, e.g. parental care and provisioning ability (Kleven et al. 1999; Grant and Sealy 2002; Soler et al. 1995, 1998; Alvarez 2004; Parejo and Avilés 2007), host female body condition (Polačiková et al. 2009) or the ability of hosts to defend their nests (Clotfelter 1998). However, the role of the host nest has rarely been studied despite the fact that brood parasites are fully dependent on them. In some thrush species, nest cup design forces common cuckoo chicks to compete with host chicks (a deeper or steeper nest cup makes egg eviction more difficult) with fatal consequences for the parasite (Grim et al 2011). Similarly, cavity nests of the common redstart (Phoenicurus phoenicurus ) have some nest design features that may prevent common cuckoo hatchlings from effectively evicting nestmates (Grim et al. 2009).

Since there have been few studies considering how particular nest designs may affect the breeding success of brood parasites, we studied the role of host nest size for survival of the common cuckoo (hereafter cuckoo) chicks. Cuckoo host species are substantially smaller than the parasite in terms of size (body length of about $14 \mathrm{~cm}$ vs. $33 \mathrm{~cm}$ in cuckoo) and weight (17 g vs. $120 \mathrm{~g}$; calculated from Snow and Perrins 1998a,b \& Erritzøe et al. 2012). As a consequence, their nests are intended for several small nestlings which in some species, even combined, do not reach the size and weight of a sole cuckoo chick occupying the host nest (Samaš et al. 2019). Reed warbler nests are small deep cups woven around strong stems, consisting mostly of grasses and reed leaves accommodating on average 3-5 own nestlings (Kennerley \& Pearson 2010). Kleven et al. (2004) reported that some cuckoo chicks were found under nests of this host from unknown reasons and it should be noted that we observed several such cases during our long-term research since 1992.

The major goal of this study is to show that the reason for these observations is that the cuckoo chick has fallen out of a nest that is too small for it. To test the role of nest size, we experimentally replaced some Eurasian reed warbler (Acrocephalus scirpaceus, hereafter RW) nests with great reed warbler (Acrocephalus arundinaceus, hereafter GRW) nests (which are approximately twice the size), expecting that these will provide more support for cuckoo chicks, and thus these chicks will fall out less frequently than cuckoo chicks remaining in RW nests. To demonstrate what happened in the nests, we continuously recorded them. Second, we tested whether the feeding effort of foster parents may affect frequency of falling-out. It has been shown that begging effort is higher in hungry than in satiated chicks (Price et al. 1996; Wright \& Leonard 2002) and hungrier chicks move more in their nests (McRae et al.1993; Dickens et al 2008). We predicted that the probability of falling-out will increase with hunger, i.e. chicks that are fed less will fall out more often because of their restlessness and movement in the nests.

\section{MATERIAL AND METHODS}

The fieldwork was conducted during four breeding seasons (2016-2019) in two adjacent fishpond areas between Hodonín (48 $\left.51^{\prime} \mathrm{N}, 17 \mathrm{deg} 07^{\prime} \mathrm{E}\right)$ and Mutěnice (48 $\left.54^{\prime} \mathrm{N}, 17 \mathrm{deg} 02^{\prime} \mathrm{E}\right)$ in South Moravia, Czech Republic. We systematically searched for RW nests in the littoral vegetation dominated by the common reed (Phragmites australis ), with a smaller proportion of the narrow-leaved cattail (Typha angustifolia). Each nest was tagged with a small piece of coloured tape and its location recorded with GPS. As a result, we found more than 250 nests each year. Of these nests, we randomly choose and continuously video-recorded 74 RW nests containing cuckoo chicks during June and July (14 in 2016, 17 in 2017, 16 in 2018 and 27 in 2019). We set up our video-cameras at the nests when cuckoos were ten days old and collected them when the cuckoo disappeared from the nest or died in the nest (one occasion, not included in analyses).

The video-recording system comprised either a rear-view camera Carmedien STO-IR (Carmedien, Tschernitz, Germany) with IR illumination or custom HD cameras with inbuilt recorders without IR illumination and miniature digital videorecorder Mini DVR CH-HD0065 (Shenzhen Chu-Tech Co. Ltd, China) placed in a 
water-resistant box. All equipment was powered by $12 \mathrm{~V} / 100 \mathrm{Ah}$ gel batteries with the capacity to record continuously for about 7 days. All equipment was camouflaged; batteries were placed on the bank ca $10 \mathrm{~m}$ from the nests and water resistant boxes with recorders were hung on reeds and covered by masked cloths two to five metres from nests. Cameras were placed on thin aluminium poles camouflaged by cut reed stems and leaves fastened together by jute string. The distance between cameras and nest varied from $20 \mathrm{~cm}$ to two meters depending on the reed stem density. Filmed nests were visited every three days to check the nest content, adjust equipment and download the data (change the memory card).

\section{Nest replacement experiment}

To find out how host nest size affects cuckoo chick survival, we replaced 33 RW nests with GRW nests. We used GRW nests because they have a similar design and material composition (Kožená-Toušková 1973; Kennerley \& Pearson 2010), occur in the same habitat (Leisler \& Schulze-Hagen 2011) and they are more than one-third larger than RW nests (mean nest diameter \pm SD: $70.5 \pm 1.5$ in RW vs. $97.5 \pm 5.2 \mathrm{~mm}$ in GRW, mean diameter of nest cup: $51.6 \pm 2.6$ in RW vs. $72.9 \pm 4.0$ in GRW, $\mathrm{N}=5$ for RW and 120 for GRW; own data). GRW nests used for this experiment were obtained from the same study site. Since GRWs often abandon their nests as a response to parasitism and then build new ones (Šulc et al. 2019), we used these abandoned nests for our experiment. These nests were attached to the reed stems at the same place as the original RW nests with jute strings on the day when the video-camera was installed and cuckoo chicks were moved from the original nest to these new ones. We did not notice any negative effect of the experimental procedure as foster parents started to feed cuckoos almost immediately after we left the nest site. Natural RW nests were not manipulated, but we avoided those loosely fastened or we fixed their attachment to reed stems by jute string as we were focused on the spatial features of nests and not the building skills of hosts. Experimental nests were checked with the same frequency as 42 non-manipulated RW nests (see above).

\section{Analysis of parental feeding}

To test how the probability of falling-out of the nest is affected by the level of cuckoo hunger, we compared the feeding behaviour of foster parents in nests from which cuckoo chicks fell out with nests where they fledged successfully. As we were focused on cuckoo state closely to the time of falling-out of the nest, we counted all parental feeding visits during the three-hour time span preceding the cuckoo chick falling-out. To test whether the feeding effort of foster parents may affect frequency of falling-out, we selected one nest where the cuckoo chick stayed in the nest (successful) as a control counterpart for each nest where the cuckoo chick fell out (unsuccessful). These successful nests were from the same breeding season, had the same nest size treatment and similar timing during the season (the mean difference \pm SD in hatching date was 4.9 \pm 4.5 days, $\max =15$ days) as the unsuccessful nests. In the successful nests, we analysed feeding visits from video-recordings in which the cuckoo chicks were of the same age as in those in assigned unsuccessful nests and from the same time because the behaviour of parents could depend on both nestling age and daytime (Požgayová et al. 2015). The final dataset comprised of 15 successful and 15 unsuccessful nests. One unsuccessful nest was excluded from the analysis because the quality of recording was not sufficient to count parental feeding visits.

\section{Statistical analysis}

We used Fisher's exact test to determine whether the fledging success of cuckoo chicks differed between smaller RW nests and larger experimental GRW nests. Only nests from which cuckoos successfully fledged and left the nest or prematurely fell out of the nest were used for this main analysis.

To test the relationship between parental feeding effort and the probability that cuckoo chick will fall out of the nest, we used generalized linear models with a binomial error distribution and logit link function in $\mathrm{R}$ 3.4.4 ( $\mathrm{R}$ Core Team 2018). The initial model consisted of the cuckoo chick fate $(0=$ chick fell out from the nest or $1=$ chick successfully fledged) as a response binomial variable, number of parental feeding visits as a continuous predictor and daytime (continual), date (continual) and year (categorical) as covariates. P-values of particular model terms were based on Type III sum of squares. 


\section{RESULTS}

Of the 73 continuously video-recorded cuckoo chicks, 45 chicks (61\%) fledged successfully, 10 chicks (14\%) were depredated, 16 chicks $(22 \%)$ fell out of the nests and two chicks $(3 \%)$ were ejected by adult cuckoos. Cuckoo chicks fell out significantly more frequently from smaller natural RW nests (12 of 32) than from larger experimental GRW nests ( 4 of $29, \mathrm{P}=0.044$, odds ratio $=0.27, \mathrm{CI}=0.06-1.08$ ). Moreover, cuckoo chicks raised in RW nests fell out of the nests at a younger age than those raised in GRW nests (Wilcoxon test, $\mathrm{P}=$ 0.024 , Fig. 1). When cuckoo chicks were falling-out from the nest, in 13 of 16 cases the nest was trampled by the chick to more or less flat platform sometimes tilted to one side. In these cases, the falling-out was caused by excessive movement on the nest triggered by: parental feeding $(\mathrm{N}=5)$ when parents typically fed the chick and then it leaned forwards or backwards and fell down, comfort behaviour of the chicks $(\mathrm{N}=7)$ when the chick e.g. hooked its wing around the reed stem or slipped from the nest rim during stretching or moving. In three occasions cuckoos fell out from an undamaged nest with a deep cup due to comfort behaviour $(\mathrm{N}=2)$ and once because it excessively moved to the side when a foster parent cleaned the nest cup.

We found a significant negative relationship (estimate $\pm \mathrm{SE}=-5.62 \pm 11.84, \mathrm{P}=0.047$ ) between the number of parental feeding visits and the probability of cuckoo falling-out of the nest (Tab. 1). Cuckoos chicks which fell out of the nest were fed less intensively during the three hours before the falling-out event than their cuckoo counterparts in nests from which they finally fledged (Fig. 2).

\section{DISCUSSION}

In the present study we have found that more than one third (12 of 32) of cuckoo chicks raised in RW nests fell out of the nest. This represents a serious cost that has apparently negative effect on the breeding success of cuckoo chicks raised by RW. This finding also helps to clarify mystery outlined by Kleven et al. (2004): "In reed warbler nests 12 of the cuckoo nestlings were depredated, 10 were found dead due to unknown reasons inside or under the nest". In light of our video-recordings, we believe that dead chicks found under the nests by Kleven et al. (2004) are consequences of falling-out events. One can speculate that the falling-out events we recorded might be associated with time of fledging and/or it was prematurely induced by researchers (Pietz et al. 2012). However, this explanation is unlikely as we found that all falling-out events happened several days before expected time of fledging and several hours after the last nest check by the researchers.

Interestingly, our video-recordings show that falling-out was caused by insufficient nest design. RW nests are small deep cups which cuckoo chicks only fitted in during the first half or two thirds of their nestling period. Later the chicks frequently damaged the nest and sat only on a trampled nest remnant. When standing on this flat platform cuckoo chicks were very susceptible to losing balance during stretching or moving and easily fell down. In contrast, larger GRW nests have more spacious nest cups which comfortably accommodated growing cuckoo chicks for a longer time than the RW nests. Moreover, GRW nests are also more solid with thicker walls and thus endured without fundamental damage much longer - often even till the moment of fledging. As a result falling-out events happened in GRW not only less frequently than in RW nests but also later in the nestling period (after 15 days of age).

This result may also provide an alternative explanation for why parasites prefer to lay their eggs in larger host nests. Previous studies that observed the nest choice of brood parasites (Kleven et al. 2004; MolinaMorales et al. 2013, 2016) suggested that host pairs (females and/or males) that built bigger nests are better quality and can also feed the parasitic chick better. However, we suggest that the preference for bigger nests may be explained by their better physical suitability for raising parasitic chicks. This hypothesis, however, requires further testing.

We also found that the probability of falling-out positively increases with hunger, i.e. that less well-fed chicks fall out more frequently. We speculate that these less satiated chicks are hungrier and thus they are restless and may beg more vigorously in their nests which can lead to the accidental fall-out events. Indeed, it has been shown that nestlings beg more intensively when they are hungrier (Smith \& Montgomerie 1991; Price et al. 1996; Wright \& Leonard 2002) and their begging is positively related to more active movement (McRae et al.1993; Dickens et al 2008). It must be noted, that the cuckoo chick is raised alone and does not have 
to compete with other siblings by jockeying and moving to a position where parents are more likely to feed them (McRae et al. 1993). Yet, begging reliably signals short-term need (Searcy \& Nowicki 2005), therefore we believe that falling-out events may be associated with lower feeding frequency.

The phenomenon of nestlings leaving their nests before they reached fledging age has also been observed in many other species like Mississippi kite (Ictinia mississippiensis), northern caracara (Caracara cheriway), barn swallow (Hirundo rustica) and moustached warbler (Acrocephalus melanopogon), when they fall out (von Vietinghoff-Riesch 1955; Morrison 1999; Bader \& Bednarz 2009), jump from (Kleindorfer et al. 1996) or are pushed out of their nests (Bader \& Bednarz 2009). Interestingly, there is an apparent gap in knowledge of factors that act as triggers for these events.

The cost of falling-out differs depending on the habitat. In the RW, the cuckoo chicks that fell out drowned (4 of 16) or prematurely disappeared without trace from the territory (7 of 16) in most cases. Therefore, parasitizing host species that nest above the water can have a high cost, suggesting that specialization on such a host can become an evolutionary trap. Despite this, the RW is the most frequent cuckoo host in Europe (Moksnes \& Røskaft 1995) which presumably implies that this host is otherwise very suitable, e.g. because it breeds in high densities in a relatively small area (Jelínek et al. 2016), does not defend its nest aggressively (Honza et al. 2004) or accepts cuckoo eggs at a high rate (Šulc et al. 2019).

We also advocate video surveillance of bird nests. This method revealed that the misclassification of factors leading to nest failure or loss of eggs/nestlings is relatively common (Pietz \& Granfors 2000). In particular, overestimation of predation rate can potentially lead to false results and conclusions. Similarly to this study, previous studies have reported a relatively low fledgling and/or breeding success of cuckoos raised by the RW (Honza et al. 1998; Jelínek et al. 2016). Although these authors considered disappearance of the cuckoo chick as predation, we suspect in light of our new findings that predation has been overestimated and falling-out might have a strong effect as well. In fact, in our 74 video-monitored nests the fall-out was the main reason for nest failure (16 cuckoo chicks fell out, 12 were predated and one died in the nest). Nevertheless, survival rates of RW nests (Jelínek et al. 2016) or nests of other species breeding in reedbeds (Neto \& Gosler 2005; Musilová et al. 2014) are high in comparison with species breeding in open or woodland habitats (Weidinger 2006; Praus et al. 2014) where nest predation is the main source of nest failure (Ricklefs 1969; Martin 1993). This suggests that the cost for cuckoos induced by the fall-out from RW nests can be compensated by low nest predation rate in this habitat.

To conclude, the frequent falling-out of cuckoo chicks observed in this study represents serious costs that substantially reduce the breeding success of the parasite. We demonstrate that both the insufficient host nest size and insufficient parental feeding may be contributing factors. This cost of falling-out can be in the same time counterbalanced by gains from low nest predation, high breeding densities or low rejection rate of parasitic eggs. Further studies are needed on different brood-parasitic systems like those in the Americas represented by cowbirds (Molothrus spp.) and their hosts. A host breeding over water such as the redwinged blackbird (Agelaius phoeniceus ), would be a particularly suitable model to examine whether this cost is species-specific or whether it is more widespread across different brood parasitic systems. Finally, it would also be interesting to study whether accidental falling-out events in nests above the ground can positively affect brood parasite fitness because concealment in vegetation may become advantageous for nestling survival. We believe that these areas are fruitful avenues for future research.

Acknowledgements

The research was conducted in compliance with ethical guidelines. We are obliged to local nature conservation authorities for allowing us to work on wild protected animals (Czech permit numbers JMK20189/2010, JMK23530/2011, MUHOCJ 41433/2012, JMK115874/2013, MUHOCJ 34437/2014). The study was supported by the Czech Science Foundation (project17-12262S) and by the Institutional Research Plan (RVO: 68081766).

\section{AUTHORSHIP}


MH designed the study, MH and MŠ collected the data, MC a VJ analysed the data, MH, MC, VJ and MŠ wrote the manuscript.

\section{References}

Alvarez, F. (2004). The conspicuous gape of the nestling common Cuckoo Cuculus canorus as a supernormal stimulus for Rufous Bush Chat Cercotrichas galactotes hosts. Ardea 92, 63-68.

Bader, T.J. \& Bednarz, J.C. (2009). Reproductive success and causes of nest failures for Mississippi kites: A sink population in eastern Arkansas? Wetlands, 29, 598-606.

Capek, M., Požgayová, M., Procházka, P. \& Honza, M. (2010). Repeated presentations of the Common Cuckoo increase nest defence by the Eurasian Reed Warbler but do not induce it to make recognition errors. Condor, 112, 763-769.

Clotfelter, E.D. (1998). What cues do Brown-headed Cowbirds use to locate Red-winged Blackbird nests? Anim. Behav., 55, 1181-1189.

Dickens, M., Berridge, D. \& Hartley, I.R. (2008). Biparental care and offspring begging strategies: hungry nestling blue tits move towards the father. Anim. Behav., 75, 167-174.

Erritzøe, J., Mann, C.F., Brammer, F.P., Fuller, R.A. (2012). Cuckoos of the World. Christopher Helm/Bloomsbury Publishing Plc, London.

Gill, F., Donsker, D. \& Rasmussen, P. (eds.). (2020). IOC World Bird List (v10.1). Available at: doi : 10.14344/IOC.ML.10.1., Last accessed 04. 02. 2020.

Gloag, R., Fiorini, V.D., Reboreda, J.C. \& Kacelnik, A. (2013). The wages of violence: mobbing by mockingbirds as a frontline defence against brood-parasitic cowbirds. Anim. Behav. 86, 1023-1029.

Grant, N.D. \& Sealy, S.G. (2002). Selection of red-winged blackbird (Agelaius phoeniceus ) hosts by the brown-headed cowbird (Molothrus ater ). Bird Behav. 15, 21-30(10)

Grim, T., Rutila, J., Cassey, P. \& Hauber, M.E. (2009). Experimentally Constrained Virulence is Costly for Common Cuckoo Chicks. Ethology, 115, 14-22.

Grim, T., Samaš, P., Moskát, C., Kleven, O. \& Honza, M. (2011). Constraints on host choice: why do parasitic birds rarely exploit some common potential hosts? J. Anim. Ecol. doi: 10.1111/j.1365-2656.2010.01798.x

Hansell M. (2000). Bird nests and construction behaviour. Cambridge University Press, Cambridge.

Honza, M., Grim, T., Capek, M., Jr, Moksnes, A. \& Røskaft, E. (2004). Nest defence, enemy recognition and nest inspection behaviour of experimentally parasitized Reed Warblers Acrocephalus scirpaceus . Bird Study, 51, 256-263.

Honza M, Øien IJ, Moksnes A. \& Roskaft E. 1998. Survival of Reed Warbler Acrocephalus scirpaceus clutches in relation to nest position. Bird Study, 45: 104-108.

Jaramillo, A. \& Burke P. 1999. New World Blackbirds: The Icterids. Christopher Helm, London.

Jelínek, V., Karasová, T., Weidinger, K., Procházka, P. \& Honza, M. (2016). Do common cuckoo chicks suffer nest predation more than host nestlings? Behav. Ecol. Sociobiol., 70, 1975-1987.

Kennerley P. \& Pearson D. (2010). Reed and Bush Warblers. Christopher Helm/A\&C Black, London.

Kleindorfer, S., Hoi, H. \& Fessl B. (1996). Alarm calls and chick reactions in the moustached warbler, Acrocephalus melanopogon. Anim. Behav., 51, 1199-1206.

Kleven, O., Moksnes, A., Røskaft, E. \& Honza, M. (1999). Host species affects the growth rate of cuckoo (Cuculus canorus ) chicks. Behav. Ecol. Sociobiol., 47, 41-46. 
Kleven, O., Moksnes, A., Røskaft, E., Rudolfsen, G., Stokke, B.G. \& Honza M. (2004). Breeding success of common cuckoos Cuculus canorus parasitising four sympatric species of Acrocephaluswarblers. J. Avian Biol., 35, 394-398.

Kožená-Toušková, I. (1973). Composition of nests of birds breeding in the Phragmition plant communities. Acta Sc. Nat. Brno 7(7), 1-36.

Leisler, B. \& Schulze-Hagen, K. 2011. Reed Warblers: Diversity in a Uniform Bird Family. KNNV Publishing, Zeist.

Mann C.F. (2017). A Taxonomic Review of Obligate and Facultative Interspecific Avian Brood Parasitism. In: Avian Brood Parasitism: Behaviour, Ecology, Evolution and Coevolution (ed. Soler, M.). Springer International Publishing AG, Cham, pp 61-92.

Martin, T. E. (1993). Nest predation and nest sites. Bioscience, 43, 523-532.

McRae, S.B., Weatherhead, P.J. \& Montgomerie, R. 1993. American Robin nestlings compete by jockeying for position. Behav. Ecol. Sociobiol., 33, 101-106.

Molina-Morales, M., Martinez, J.G. \& Aviles, J.M. (2016). Criteria for host selection in a brood parasite vary depending on parasitism rate. Behav. Ecol., 27, 1441-1448.

Molina-Morales, M., Martinez, J.G., Martin-Galvez, D., Dawson, D.A., Rodriguez-Ruiz, J., Burk, T. \& Aviles, J.M. (2013). Evidence of long-term structured cuckoo parasitism on individual magpie hosts. J. Anim. Ecol., 82, 389-398.

Moksnes, A. \& Rostkaft, E. (1995). Egg-morphs and host preference in the Common Cuckoo (Cuculus canorus ): an analysis of Cuckoo and host eggs from European museum collections. J. Zool., 236, 625-648.

Morrison, J.L. (1999). Breeding biology and productivity of Florida's crested caracaras. Condor, 101, 505517.

Musilová, Z., Musil, P., Zouhar, J. \& Poláková, S. (2014). Nest survival in the reed bunting Emberiza schoeniclus in fragmented wetland habitats: the effect of nest-site selection. Ornis Fennica, 91, 138-148.

Neto, J. M. \& Gosler, A. G. (2005). Breeding biology of the Savi's warbler Locustella luscinioides in Portugal. Ardea, 93, 89-100.

Pajero, D. \& Avilés J. (2007). Do avian brood parasites eavesdrop on heterospecific sexual signals revealing host quality? A review of the evidence. Anim. Cogn., 10, 81-88.

Pietz, P. J. \& Granfors, D.A. (2000). Identifying predators and fates of grassland passerine nests using miniature video cameras. J. Wildlife Manage., 64, 71-87.

Pietz, P.J., Granfors, D.A. \& Ribic, C.A. (2012). Knowledge Gained from Video-Monitoring Grassland Passerine Nests. In: Video Surveillance of Nesting Birds. (eds. Ribic, C.A., Thompson, F.R., III. \& Pietz, P.J.). University of California Press, Berkeley, pp 3-22.

Polačiková, L., Procházka, P., Cherry, M.I. \& Honza, M. (2009). Choosing suitable hosts: common cuckoos Cuculus canorusparasitize great reed warblers Acrocephalus arundinaceus of high quality. Evol. Ecol., 23, 879-891.

Požgayová, M., Procházka, P. \& Honza, M. (2009). Sex-specific defence behaviour against brood parasitism in a host with female-only incubation. Behav. Process., 81, 34-38.

Požgayová, M., Beňo, R., Procházka, P., Jelínek, V., Abraham, M.M. \& Honza M. (2015). Lazy males and hardworking females? Sexual conflict over parental care in a brood parasite host and its consequences for chick growth. Behav. Ecol. Sociobiol., 69, 1053-1061. 
Praus, L., Hegeman, A., Tieleman, B.I. \& Weidinger, K. (2014). Predators and predation rates of skylark Alauda arvensis and woodlark Lullula arborea nests in semi-natural area in The Netherlands. Ardea, 102, 87-94.

Price, K., Harvey, H. \& Ydenberg, R. (1996). Begging tactics of nestling yellow-headed blackbirds, Xanthocephalus xanthocephalus, in relationto need. Anim. Behav., 51, 421-435.

R Core Team (2018). R. A language and environment for statistical computing. R Foundation for Statistical Computing, Vienna, Austria.

Ricklefs, R. E. (1969). An analysis of nesting mortality in birds. Sm. C. Zool., 9, 1-48.

Santema, P. \& Kempenaers, B. (2018). Complete brood failure in an altricial bird is almost always associated with the sudden and permanent disappearance of a parent. J. Anim. Ecol., 87, 1239-1250.

Samaš, P., Grim, T., Jelínek, V., Abraham, M.M., Šulc, M. \& Honza, M. (2019). No immediate or future extra costs of raising a virulent brood parasite chick. Behav. Ecol., 30, 1020-1029.

Searcy, W.A. \& Nowicki, S. (2005). The Evolution of Animal Communication: Reliability and Deception in Signaling Systems. Princeton University Press, Princeton and Oxford.

Smith, H.G. \& Montgomerie, R. (1991). Nestling American robins compete with siblings by begging. Behav. Ecol. and Sociobiol., 29, 307-312.

Snow, D.W. \& Perrins, C. M. (eds.). (1998a). The Birds of the Western Palearctic. Concise Edition. Vol. 1. Non-Passerines. Oxford University Press, Oxford \& New York.

Snow, D.W. \& Perrins C.M. (eds.) (1998b). The Birds of the Western Palearctic. Concise Edition. Vol. 2. Passerines. Oxford University Press, Oxford \& New York.

Soler, J.J., Soler M., Møller, A.P. \& Martinez, J.G. (1995). Does the great spotted cuckoo choose magpie hosts according to their parenting ability? Behav. Ecol. Sociobiol., 36, 201-206.

Soler, J.J., Møller, A.P., Soler, M. (1998). Mafia behaviour and the evolution of facultative virulence. J. Theor. Biol., 191, 267-277.

Šulc, M., Troscianko, J., Štětková, G., Hughes, A.E., Jelínek, V., Čapek, M. \& Honza, M. (2019). Mimicry cannot explain rejection type in a host-brood parasite system. Anim. Behav. 155, 111-118.

Von Vietinghoff-Riesch, A. (1955). Die Rauch-schwalbe. Dunker und Humblot, Berlin.

Wright, J, \& Leonard M.L. (2002). The Evolution of Begging: Competition, Cooperation and Communication. Kluver Academic Publishers, Dordrecht.

Weidinger, K. (2006). Validating the use of temperature data loggers to measure survival of songbird nests. J. Field Ornithol., 77, 357-364.

\section{Hosted file}

Figure 1 7-2.docx available at https://authorea.com/users/296732/articles/425756-fallout-thenew-cost-of-brood-parasitism

\section{Hosted file}

Figure 2 7-2.docx available at https://authorea.com/users/296732/articles/425756-fallout-thenew-cost-of-brood-parasitism

\section{Hosted file}

Table 1 7-2.docx available at https://authorea.com/users/296732/articles/425756-fallout-thenew-cost-of-brood-parasitism 